\title{
Assertiveness and Fear of Negative Evaluation
}

\section{among Young Adults}

\author{
Himaja Prabha $\mathrm{P}^{1 *}$, Dr. Kiran Babu $\mathrm{NC}^{2}$
}

\section{ABSTRACT}

Assertiveness is an important social skill among Young Adults that enhance their personal well-being. Assertiveness may be influenced by certain variables like Fear of Negative Evaluation, especially in social interaction situations. The purpose of the study was to analyze the relationship between Assertiveness and Fear of Negative Evaluation among Young Adults. The current study was conducted on 174 Young Adults both men and women between the age group of 18-25 years, who are residing in the cities of Hyderabad and Bengaluru. Quantitative approach was used along with Correlational research design was adopted and the sampling technique was purposive. Rathus Assertiveness Schedule (Rathus, 1978) and Brief Fear of Negative Evaluation scale (Leary, 1983) were administered on the participants to assess differences based on gender (men and women). Correlational analysis showed a moderate significant negative correlation between Assertiveness and Fear of Negative Evaluation among Young Adults. Results of t- test showed no significant difference in the level of Assertiveness and Fear of Negative Evaluation between men and women among Young Adults. The results of the study will help to develop interventions for people with low levels of Assertiveness and will also help to develop interventions for people with high levels of Fear of Negative Evaluation.

\section{Keywords: Assertiveness, Fear of Negative Evaluation and Young Adults}

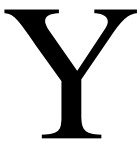

oung Adults are those who are too old to be a child and too young to be an adult. The Educational Resources Information Clearinghouse (ERIC), for example, defines Young Adults "as those between the ages of eighteen and twenty-two", whereas the National Assessment of Educational Progress (NAEP), administered by the Educational Testing Service, refers to "Young Adults, ages 21 through 25." It is the age where they focus more on how to balance between career and to maintain interpersonal relationships, which become their primary goals. Human beings are social creatures that desire and need to be belong and involved in social interactions and relations. Young Adult's identity is formed through understanding of themselves in the context of social interaction. Through social interaction Young Adults tend to form strong interpersonal relationships and thus helps them to develop social skills. Assertiveness is an important social skill among Young Adults that

\footnotetext{
${ }^{1}$ Student, Department of Psychology, Kristu Jayanti College, Bengaluru, Karnataka, India

${ }^{2}$ Assistant Professor, Department of Psychology, Kristu Jayanti College, Bengaluru, Karnataka, India *Corresponding Author
}

Received: March 19, 2021; Revision Received: April 12, 2021; Accepted: May 03, 2021

(C) 2021, Himaja Prabha P \& Kiran Babu NC.; licensee IJIP. This is an Open Access Research distributed under the terms of the Creative Commons Attribution License (www.creativecommons.org/licenses/by/2.0), which permits unrestricted use, distribution, and reproduction in any Medium, provided the original work is properly cited. 
enhance their personal well-being. Assertiveness may be influenced by certain variables like Fear of Negative Evaluation, especially in social interaction situations.

Assertiveness involves appropriately expressing one's own feelings and ideas while respecting other's rights. Systematic studies of Assertiveness began in the late 1940s and 1950s when psychologists believed that mental illness is caused due to non-assertiveness and inability to express feelings and ideas openly. Assertiveness was first defined by Wolpe and Lazarus (1966) "as all socially allowable expressions of personal rights and feelings". In order to create a more behavioral definition, Alberti and Emmons (2017) indicated that "assertive people are able to behave in their own best interests without having extreme anxiety or ignoring rights of others".

Fear of Negative Evaluation was defined as "apprehension about others' evaluations, distress over their negative evaluations, avoidance of evaluative situations, and the expectation that others would evaluate oneself negatively" (Watson \& Friend, 1969). High Fear of Negative Evaluation may operate in situations like talking to one's superior, being on a date or being in an interview for a job. But individuals with high Fear of Negative Evaluation will work hard than individuals with low Fear of Negative Evaluation in a boring task if they were told that they will be evaluated by others. Thus, individuals with high Fear of Negative Evaluation undertake behaviors in order to avoid negative evaluations by others. (Watson \& Friend, 1969).

\section{REVIEW OF LITERATURE}

Assertiveness is a way of personal behaviour and communication characterized by a willingness to stand up for one's needs and interests in an open and direct way. In the study the researcher aimed to study the Assertiveness level of undergraduate students with reference to their gender, residence and stream of study. The sample of the study is consisted of 100 undergraduate students (50 males and 50 females) within the age group between 16 to 22 years and has been the students of following courses; Bachelor of Science, Arts and Commerce. The Rathus Assertiveness Schedule (1978) was administered to study the level of Assertiveness among the students. The results of the study revealed that there was no significant difference between students in their level of Assertiveness with respect to gender, residence and stream of study (Parray \& Kumar, 2016).

In another study which was conducted to measure sex differences in assertive behavior found that men reported greater tendency to assert themselves than women in public situations while, women reported a tendency to be more assertive in private interpersonal settings. Men reported a significantly greater tendency than women to be shy in dating situations. Finally, men reported a greater willingness than women to question publicly a person of high status (Mathison et al., 1982).

Furthermore, Crassini, Law and Wilson (2007), performed a discriminant analysis of responses to the Rathus Assertiveness Schedule (RAS) to investigate sex-related differences in Assertiveness. They found that men were more assertive than women on some items and on some items, women were more assertive than men. But on a significant number of items of RAS the analysis revealed that they was no difference between men and women.

A study conducted by Pourjali and Zarnaghash (2010), aimed to understand the relationship between Assertiveness, the power of saying no with Mental health on a group of undergraduate students in Shiraz University. The sample consisted of 120 undergraduate

(c) The International Journal of Indian Psychology, ISSN 2348-5396 (e)| ISSN: 2349-3429 (p) | 409 
students including 62 women and 58 men. The data were analyzed by Pearson coefficient and independent t-Test. The results revealed that there was a significant relationship between Assertiveness and Mental health and also there was a significant relationship between the power of saying no and Mental health. But there was no significant difference between the Assertiveness of women and men and also there was no significant difference between the power of saying no, of women and men.

Ezer (2020), examined the predictive role of shyness and Fear of Negative Evaluation on Assertiveness among adolescents. The sample consisted of 419 high school students both men and women. Scales like Interpersonal Behavior (SIB), Shyness Scale, Brief Fear of Negative Evaluation Scale (BFNE) and a demographic information form were used to gather data and multiple regression analysis was performed. The results of the study revealed that shyness was found as a significant negative predictor of Assertiveness but Fear of Negative Evaluation did not reveal as a significant predictor. However, the results also revealed a significant relationship between Assertiveness and both gender and grade level of the students.

According to Sunkarapalli and Agarwal (2017), Fear of Negative Evaluation causes difference between how an individual processes information about himself and how he processes information about others in a social evaluative situation. An individual evaluates more negatively than he would evaluate another individual. They examined the relationship between Fear of Negative Evaluation and perfectionism. The sample consisted of 200 Young Adults between the age group of 18-27 years. Fear of Negative Evaluation scale and the Multidimensional Perfectionism Scale were used to collect the data and IBM SPSS software, version 24 was used for the analysis of data. The results of the present study revealed a significant positive correlation between Fear of Negative Evaluation and Perfectionism, mainly socially prescribed perfectionism.

According to Biolcati (2017), compulsive behavior is a major threat as it causes a disturbance in everyday functioning and may result in serious financial and psychological problems. This study investigated gender differences in the relationships between contingent self-esteem (CSE), Fear of Negative Evaluation (FNE), and compulsive buying. The sample consisted of 240 Italian adults. The results revealed that women scored higher on CSE and FNE scales than men. There were no gender differences found in compulsive buying tendencies. Interestingly, only for women FNE seems to play a mediating role between CSE and compulsive buying behaviors.

In another study conducted by Talat and Aslam (2012), examined the relationship between Fear of Negative Evaluation and psychological distress among addicts and non addicts. The sample consisted of 200 male adults including drug addicts $(\mathrm{n}=100)$ and non addicts $(\mathrm{n}=$ 100). Pearson Correlation, t-test and ANOVA were computed to perform the analysis. Results revealed that Fear of Negative Evaluation was positively correlated with psychological distress. Furthermore, Fear of Negative Evaluation and psychological distress were higher among addicts than non addicts.

According to Kumar et al., (2015), Fear of Negative Evaluation is one of an important psychological factor which negatively influences performance of students. The aim of the study was to understand the relationship between these psychological factors of students deeply. The sample consisted of 64 VIT University students studying in different branches of engineering. Scales used in this study are Fear of Negative Evaluation and State Trait 
Anxiety Inventory. The results revealed that there was a significant positive relationship between anxiety and Fear of Negative Evaluation.

Button and his colleagues (2015), had predicted that Fear of Negative Evaluation would bias learning about the self but not others. They conducted a research on Fear of Negative Evaluation Biases Social Evaluation Inference: Evidence from a Probabilistic Learning Task on 100 participants. The results revealed that Fear of Negative Evaluation is associated with differences in processing social-evaluative information about the self. Individuals with low Fear of Negative Evaluation manifested insensitivity to learning negative self-referential evaluation. Individuals with high Fear of Negative Evaluation are sensitive to learning positive or negative evaluation.

Karabulut et al., (2013), aimed at investigating Fear of Negative Evaluation of young national kick-boxers in terms of some variables. The sample consisted of 41 kick-boxers including 23 female kick-boxers and 18 male kick-boxers. Statistical analysis of the data, such as frequency (n), percentages $(\%)$ and non-parametric test -Mann-Whitney $U$ test were employed. Results of the study revealed that the level of Fear of Negative Evaluation of young national kick-boxers was not statistically different in terms of gender variable. But however, full contact kick-boxing and having a close/emotional friend from opposite sex affected their level of Fear of Negative Evaluation negatively.

\section{METHODOLOGY}

\section{Research questions}

1. Is there a significant relationship between Assertiveness and Fear of Negative Evaluation among Young Adults?

2. Is there any significant difference in the levels of Assertiveness between men and women among Young Adults?

3. Is there any significant difference in the levels of Fear of Negative Evaluation between men and women among Young Adults?

\section{Objectives}

1. To find if there is a significant relationship between Assertiveness and Fear of Negative Evaluation among Young Adults.

2. To find if there is any significant difference in the levels of Assertiveness between men and women among Young Adults.

3. To find if there is any significant difference in the levels of Fear of Negative Evaluation between men and women among Young Adults.

\section{Hypotheses}

$\mathrm{H}_{0} 1$ : There is no significant relationship between Assertiveness and Fear of Negative Evaluation among Young Adults.

$\mathrm{H}_{0}$ 2: There is no significant difference in the levels of Assertiveness between men and women among Young Adults.

$\mathrm{H}_{0} 3$ : There is no significant difference in the levels of Fear of Negative Evaluation between men and women among Young Adults.

\section{Research Design}

Quantitative approach was followed for the study. Correlational research design was used. 


\section{Sampling and Techniques}

The sample of the present study comprised of 174 Young Adults (56 men and 116 women). They belong to the age range of 18 to 25 years. Purposive sampling technique was applied for collecting sample of 174 Young Adults (56 men and 116 women) from the cities of Hyderabad and Bengaluru. Quantitative approach was followed for the study. Correlational research design was used.

The data was collected by using two questionnaires, the Rathus Assertiveness Schedule (RAS) and Brief Fear of Negative Evaluation (BFNE) scale and the questionnaires were to filled by individuals via Google form. Participants were provided with Rathus Assertiveness Schedule (RAS) to measure their levels of Assertiveness along with Brief Fear of Negative Evaluation (BFNE) scale to measure anxiety associated with perceived negative evaluation.

\section{Tools for the study}

Rathus Assertiveness Schedule (RAS) by Spencer Rathus (1978) and Brief Fear of Negative Evaluation (BFNE) scale by Leary (1983).

Description of the tool,

1. The Rathus Assertiveness Schedule (RAS) was developed by Spencer Rathus (1978) and is used to study the level of Assertiveness. It is a standardized tool comprising of 30 situational statements for which the subject is asked to rank the degree to which each statement is characteristic and descriptive of his/her behavior $(-3$ to +3$)$ yielding a total Assertiveness score between -90 (least assertive) and +90 (most assertive). There was no time limit for completion of the scale. Reliability is .82 for the RAS. Items are rated in terms of how descriptive the item is of the respondent. Ratings are from +3 to -3 . Seventeen items, indicated by an asterisk on the scale, are reversed scored. Scores are determined by summing items rating, and can range from -90 to +90. Negative scores indicate no Assertiveness and positive scores indicate Assertiveness.

2. Brief Fear of Negative Evaluation (BFNE) scale was originally developed by Leary (1983) to measure anxiety associated with perceived negative evaluation. It is a brief, 12-item version of the original 30 item scale. Result of the Leary's (1983) study showed that psychometric properties of the scale were nearly identical with the fulllength scale. Participants rate the items on a 5-point Likert scale ranging from 1 (not at all characteristics of me) to 5 (extremely characteristics of me). Reliability is .97 for the BFNE. Brief Fear of Negative Evaluation Scale scores are calculated by reversing scores on four items; 2, 4, 7, 10. Then, all scores are summed. Total scores that can be obtained from the scale change 12 to 60. Higher scores reflect greater Fear of Negative Evaluation.

\section{Inclusion criteria}

1. Young Adults of age 18-25 were included in the study.

2. All genders included were in the study.

3. Young Adults from cities of Hyderabad and Bangalore were included in the study.

\section{Exclusion Criteria}

1. Any other city other than Hyderabad and Bangalore were excluded from the study.

2. Individuals above the age of 25 were excluded from the study.

3. Individuals below age 18 years were excluded.

4. Participants who cannot follow English Language. 


\section{Procedure}

After selecting the measures, a few arrangements were made for collection of the data. The questionnaires and information sheets were prepared and organized. The study was initiated by choosing those individuals who are between 18-25 years. Informed consent was taken from the participants and were asked to fill the questionnaire through Google form, from a link sent to them. In addition to the written instructions, they were also encouraged to seek clarification on any aspect related to the study. The questionnaires were self-administered by those who could read and write. On an average the time taken to administer the scale was twenty to twenty-five minutes.

\section{RESULTS AND DISCUSSION}

The purpose of the study was to analyze the relationship between Assertiveness and Fear of Negative Evaluation among Young Adults. The data was collected through Google Forms using Rathus Assertiveness Schedule (RAS) and Brief Fear of Negative Evaluation (BFNE) scale. Total sample size was 174 Young Adults within the age group of 18-25 years residing in cities of Hyderabad and Bengaluru were selected. The data was entered into Microsoft Excel and then exported into SPSS 20 for statistical analysis.

Ho1: There is no significant relationship between Assertiveness and Fear of Negative Evaluation among Young Adults.

Table 1 Correlation between Assertiveness and Fear of Negative Evaluation among Young Adults

\begin{tabular}{lcc}
\hline $\mathbf{N}=\mathbf{1 7 4}$ & Assertiveness & Fear of Negative Evaluation \\
\hline Assertiveness & & $-.437^{* *}$ \\
Fear of Negative Evaluation & $-.437^{* *}$ & \\
\hline Note: p<0.01** is significant at the 0.01 level $(2-t a i l e d$ &
\end{tabular}

Note: $\mathrm{p}<0.01 * *$ is significant at the 0.01 level (2-tailed).

The correlation was calculated for the two variables, i.e., Assertiveness and Fear of Negative Evaluation for 174 Young Adults. The Pearson correlation results showed that there was a moderate significant negative correlation between Assertiveness and Fear of Negative Evaluation $(r=-.437, \mathrm{p}<0.01)$, indicating that higher levels of Assertiveness were related to lower levels of Fear of Negative Evaluation. Therefore, rejecting the null hypothesis.

The finding of the present study was supported by a research conducted by Ezer (2020) found that there was a weak significant negative correlation between Assertiveness and Fear of Negative Evaluation. Findings of Lefevre and West (1981), which suggested that lowassertive students have fear of disapproval than high-assertive students. This can be possibly because they restrict to express oneself around others, tendency to experience negative emotions and have negative attitude towards oneself (Krist, 2011).

$\mathrm{H}_{0}$ 2: There is no significant difference in the levels of Assertiveness between men and women among Young Adults.

Table 2 Independent t test of Assertiveness among Young Adults based on gender

\begin{tabular}{lrcccccl}
\hline Assertiveness & $\mathbf{N}$ & Mean & SD & SE & t & df & p-value \\
\hline Men & 56 & 3.053 & 22.82 & 3.05 & .91 & 170 & .33 \\
Women & 116 & 6.26 & 19.05 & 1.76 & & & \\
\hline
\end{tabular}

Note: $D V=$ Assertiveness, $S D=$ Standard Deviation, $S E=$ Standard Error

(C) The International Journal of Indian Psychology, ISSN 2348-5396 (e)| ISSN: 2349-3429 (p) | 413 
An independent sample t-test was conducted to compare the differences between Assertiveness among Young Adults based on gender. The results revealed that there was no significant difference in the scores of Assertiveness among men $(\mathrm{M}=3.05, \mathrm{SD}=22.82)$ and women $(\mathrm{M}=6.26, \mathrm{SD}=19.05)$ indicating that women have higher Assertiveness levels compared to men. Therefore, accepting the null hypothesis.

The finding of the present study was supported by previous researchers like Mathison et al. (1982) where they found that women are more assertive than men in private interpersonal settings. Ezer (2020) found that females scored higher means of Assertiveness than males. In another study conducted by Crassini et al. (2007) revealed that women reported to be more assertive than men on some items. However, in few studies men are more assertive than women (Coşkuner et al., 2013; Kimble et al., 1984). The hypothesis of this study stating that there will be no significant difference in the levels of Assertiveness between men and women has been accepted. In a research conducted by Parray et al. (2016), found that there was no significant difference in the levels of Assertiveness between boys and girls. Although, there is no significant difference women are more assertive than men. This can be because women are willing to express themselves whereas, men do not much express in social situations.

\section{Ho3: There is no difference in the levels of Fear of Negative Evaluation between men and women among Young Adults.}

Table 3 Independent t test of Fear of Negative Evaluation among Young Adults based on gender

\begin{tabular}{llllllll}
\hline $\begin{array}{l}\text { Fear of } \\
\text { Negative } \\
\text { Evaluation }\end{array}$ & N & Mean & SD & SE & t & df & p-value \\
\hline Men & 56 & 32.55 & 6.87 & .91 & .41 & 170 & .70 \\
Women & 116 & 33.06 & 8.92 & .82 & & & \\
\hline
\end{tabular}

Note: $D V=$ Fear of Negative Evaluation, $S D=$ Standard Deviation, $S E=$ Standard Error

An independent sample t-test was conducted to compare the differences between Fear of Negative Evaluation among Young Adults based on gender. The results revealed that there was no significant difference in the scores of Fear of Negative Evaluation among men $(M=$ 32.55, $\mathrm{SD}=6.87)$ and women $(\mathrm{M}=33.06, \mathrm{SD}=8.92)$ indicating that women have a higher Fear of Negative Evaluation compared to men. Therefore, accepting the null hypothesis.

The finding of the present study was supported by previous researcher like Biolcati (2017) found that women have a higher Fear of Negative Evaluation than men. Karabulut et al. (2013) found that there was no significant difference based on gender in the levels of Fear of Negative Evaluation, but however after analyzing the mean scores it was found that women have a higher Fear of Negative Evaluation when compared to men. In another study conducted by Sunkarapalli et al. (2017) revealed that there was no significant difference in the levels of Fear of Negative Evaluation between men and women, thus supporting the hypothesis of this study stating that there is no significant difference in the levels of Fear of Negative Evaluation between men and women. Although, there is no significant difference women have high Fear of Negative Evaluation than men. This could be possibly because of the discrimination women face and also may be because the society and family expect women to possess certain qualities which may make them sensitive (Sunkarapalli et al., 2017). 


\section{CONCLUSION}

- The results interpreted showed there was a moderate significant negative correlation between Assertiveness and Fear of Negative Evaluation among Young Adults.

- The study revealed that there was no significant difference in the levels of Assertiveness between men and women among Young Adults. But it was noted that women $(M=6.26, S D=19.05)$ have higher Assertiveness levels compared to men $(\mathrm{M}=3.05, \mathrm{SD}=22.82)$.

- The study also revealed that there was no significant difference in the levels of Fear of Negative Evaluation between men and women among Young Adults. It was noted that women $(\mathrm{M}=33.06, \mathrm{SD}=8.92)$ have higher Fear of Negative Evaluation compared to men $(\mathrm{M}=32.55, \mathrm{SD}=6.87)$.

\section{Implications}

- The findings of the present study can be used to develop interventions for people with low levels of Assertiveness.

- The findings will also help to develop interventions for people with high levels of Fear of Negative Evaluation.

- If the levels of Fear of Negative Evaluation are reduced then the individual can be more assertive, as the literature shows that lower level of Assertiveness is significantly related to higher level of social anxiety (Tagay et al., 2018).

\section{Limitations}

- As the sample was taken only from a particular geographical area (Hyderabad and Bengaluru city) it cannot be generalized to the whole population.

- The sample of the study included Young Adults between the age group of 18-25 years. The study could be conducted on a different age group.

- Participants had to fill the questionnaire online. This could have affected the concentration of participant resulting in inaccurate responses.

\section{REFERENCES}

Alberti, R., \& Emmons, M. (2017). Your perfect right: Assertiveness and equality in your life and relationships. California: New Harbinger Publications.

Biolcati, R. (2017). The Role of Self-esteem and Fear of Negative Evaluation in Compulsive Buying. Frontiers in Psychiatry.

Button, K. S., Kounali, D., Stapinski, L., Rapee, R. M., Lewis, G., \& Munafò, M. R. (2015). Fear of Negative Evaluation biases social evaluation inference: evidence from a probabilistic learning task. PloS one, 10, 4.

Crassini, B., Law, H. G., \& Wilson, E. (2007). Sex differences in assertive behaviour. Australian Journal of Psychology.

Ezer, S. I. (2020). Shyness and Fear of Negative Evaluation as predictors of Assertiveness. The graduate school of social sciences of Middle east technical university.

Karabulut, E. O., Bahadir, Z., Certel, Z., \& Pulur, A. (2013). Investigation of fears of negative evaluation of young national kick boxers in terms of some variables. Physical Education and Sport/Science, Movement and Health Series: Ovidius University Press.

Kimble, C. E., Marsh, N. B., \& Kiska, A. C. (1984). Sex, age, and cultural differences in self-reported assertiveness. Psychological Reports, 55, 2, 419-422. doi:10.2466/pr0.1984.55.2.419 
Kirst, L. K. (2011). Investigating the relationship between assertiveness and personality characteristics. University of Central Florida, Florida.

Kumar, G., Athilakshmi, R., Maharishi, R., \& Maya, R. (2015). Relationship between Fear of Negative Evaluation and Anxiety. The International Journal of Indian Psychology.

Leary, M. R. (1983). A brief version of the Fear of Negative Evaluation Scale. Personality and Social Psychology Bulletin, 9, 3, 371-375.

Lefevre, E. R., \& West, M. L. (1981). Assertiveness: Correlations with self-esteem locus of control, interpersonal anxiety, fear of disapproval, and depression. Psychiatric Journal of the University of Ottawa, 6, 4, 247-251.

Mathison, D. L., \& Tucker, R. K. (1982). Sex Differences in Assertive Behavior: A Research Extension. Sage Journals.

Nilsen, A. P., \& Donelson, K. L. (2009). Literature for Today's Young Adults. Pearson Education.

Parray, W. M., \& Kumar, S. (2016). Assertiveness among Undergraduate Students of the University. The International Journal of Indian Psychology, 4.

Pourjali, F, \& Zarnaghash, M. (2010). Relationships between Assertiveness and the power of saying no with Mental health among undergraduate student. Procedia - Social and Behavioral Sciences, 9, 137-141.

Rathus, S. A. (1973). Rathus Assertiveness Schedule. Behavior Therapy, 4, 398-406.

Sunkarapalli, G., \& Agarwal, T. (2017). Fear of Negative Evaluation and Perfectionism in Young Adults. IOSR Journal of Humanities and Social Science, 22, 53-60.

Tagay, Ö., Önen, Ü. Ö., \& Canpolat, İ. (2018). Relationship among adolescents' social anxiety, assertiveness and self-esteem. Afyon Kocatepe University Journal of Social Sciences, 20, 2, 261-269.

Talat, K., \& Aslam, N. (2012). Fear of Negative Evaluation and Psychological Distress among Patients of Drug Addiction. Journal of the Indian Academy of Applied Psychology, 39, 44-54.

Watson, D., \& Friend, R. (1969). Measurement of social-evaluative anxiety. Journal of Consulting and Clinical Psychology, 33, 4, 448-457. doi: 10.1037/h0027806

Wolpe, J., \& Lazarus, A. A. (1966). Behavior therapy techniques. New York: Pergamon Press.

Zeki Coşkuner. (2013). A Study on Assertiveness Level of College Students who are doing Orienteering Sports. Advances in Environmental Biology, 7, 4, 725-729.

\section{Acknowledgement}

The author(s) appreciates all those who participated in the study and helped to facilitate the research process.

\section{Conflict of Interest}

The author(s) declared no conflict of interest.

How to cite this article: Himaja Prabha P \& Kiran Babu NC (2021). Assertiveness and Fear of Negative Evaluation among Young Adults. International Journal of Indian Psychology, 9(2), 408-416. DIP:18.01.042.20210902, DOI:10.25215.0902.042 